\title{
Girişimcilik ve İnovasyon'un Küme Oluşumunda Önemi ve Devlet Yardımlarının Etkisi
}

\author{
Meral Sayın ${ }^{a}$, Erol Sayın ${ }^{\mathrm{b}}$ \\ aÇankaya Üniversitesi, Girişimcilik ve İnovasyon Araştırma ve Uygulama Merkezi, Ankara \\ ${ }^{\mathrm{b} K a r a b u ̈ k}$ Üniversitesi, Endüstri Mühendisliği Bölümü, Karabük
}

\begin{abstract}
$\ddot{O} z$
Kümelenmenin kuramsal temelinde, yı̆̆ılım ekonomileri, inovasyon ve rekabet avantajı ile kümelerin yakın ve uzak bağlantıların konu alan ă̆ yapıları (network) kuramının olduğu bilinmektedir. Bu kapsamda kümenin ve girişimcilerin rekabetçiliği için iç ve dış çeore koşulları, küme oyuncularn ile aralarındaki ilişkiler ve etkileşimden kaynaklanan küme iç dinamiği de önemlidir. Ülkemizde halen birçok kurum ve kuruluşun kümelenmeyi destekleyen programlar yürürlü̈̆e koyduğu bilinmektedir. Ayrıca kümelenme sürecini başlatan ve geliştiren girişimcilik ve inovasyon için de destekler bulunmaktadır. Bu bildiride, söz konusu destek mekanizmalarının küme çevre koşulları ve küme iç dinamiği ile ilgili hangi yönde destekleme ve geliştirme ortaya koyduğunun analizi yapılarak önerilerde bulunulmaktadır.
\end{abstract}

Anahtar Kelimeler: Kümelenme, Küme Destek Programları

\section{The Importance of Entrepreneurship and Innovation in Cluster Formation and The Effect of State Aid}

\begin{abstract}
It is known that theoretical background of business clusters is composed of by agglomeration economies, innovation with competitive advantage and networking which indicate close and distant linkages of clusters. In this line, internal and external environmental conditions and cluster dynamism, formed by cluster actors and interactions amongst them carry utmost importance for competitiveness of both clusters and cluster members. Recently, many support programmes have been put in action to support cluster initiatives in Turkey by various institutions. In addition it is also known that there are many programmes supporting entrepreneurship and innovation in Turkey, which initiate and develop clustering process. This paper aims at making evaluations and recommendations regarding these support mechanisms by analyzing how these current support mechanisms develop cluster dynamism and environmental conditions of clusters.
\end{abstract}

Key words: Clustering and cluster Support Programmes

\section{GİRIŞ}

$\mathrm{Bu}$ bildirinin amacı, bir taraftan yerel ve bölgesel kalkınma için özellikle 1990'ların ortalarından itibaren bir çok gelişmiş ve gelişmekte olan ülkede etkin bir araç olarak yararlanılan kümelenmenin kuramsal temelinde yer alan bileşenlerin incelenmesi ve buna dayanarak kümelenmede girişimcilik, inovasyon ve ağ yapılanmanın öneminin ortaya konması ile ilgilidir. Buna ilave olarak ülkemizde yürürlükte bulunan kümelenme ile ilgili destek mekanizmalarının genel seviyede bir taraması yapılarak girişimcilik, inovasyon ve ağ yapılanmayı hangi düzeyde desteklediklerine ilişkin değerlendirmeler yapılmaktadır. 


\section{KÜMELENMENIN KURAMSAL TEMELI}

Çağımızda yerel ve bölgesel kalkınma için etkin bir araç olarak yararlanılan kümelenmenin kuramsal temelinde, yığılım ekonomileri, inovasyon ve rekabet avantajı ile kümelerin yakın ve uzak bağlantılarını konu alan ağ yapıları (network) kuramının olduğu bilinmektedir. Bu kapsamda kümelenmenin geçmişi, ünlü iktisatçı Marshall'ın 1890 yılında ortaya koyduğu; üretimin belli bir coğrafi alanda yoğunlaşmasının üreticilere belli bir dişsal ekonomi sağlamasını konu alan yığılım ekonomileri kuramından gelmektedir. Yığılım ekonomileri kuramı ile ilgili olarak 1990'a kadar önemli bir aşama kaydedilmemiştir. Yığılım ekonomilerine bilgi ve iletişim teknolojilerinin yansıması ile e-ticaret, e-iş ve ağ yapılanmanın getirdiği verimlilik artışı şeklinde katkılar, sırasıyla 1990 ve 1996 yıllarında Romer ve Bapista tarafından yapılmıştır. Ancak asıl önemli katkı 1998 yılında "inovasyon ve rekabet avantajı” yaklaşımı ile İktisatçı Michael Porter'dan gelmiştir (Kuah, 2002).

Porter, 1998'de "rekabet elmas modeli"ni ortaya koyarak yerel ve bölgesel kalkınma için "küme rekabetçiliği" şeklinde bir kavramın da ortaya çıkmasını sağlamıştır (Porter, 2009). Bunlara ilave olarak "kümenin yakın ve uzak bağlantıları" konusunda da "kümenin sinırlarının kol ucu mesafesinde olduğunu" ifade ederek, pazara ya da hammaddeye yakınlığın önemini kaybettiğini ve uzak mesafelerde de bunlara ulaşaılabileceğini belirtmiştir. Bu kapsamda özellikle ileri teknoloji firmaları açısından eğitim ve öğretim kurumlarına, Ar-Ge merkezlerine, mevzuat danışma bürolarına, kamu kurumlarına yakınlığın, sağladıkları dışsal ekonomi sebebi ile daha fazla önem taşıyabileceğini kaydetmiştir. Bu bağlamda yerel ilişkiler, değerler ve motivasyonun da önem kazandığı ortaya konmaktadır (Kuah, 2002).

Bu kapsmada yığılım ekonomilerinin içerisinde girişimcilik ve inovasyonun, yerel ve bölgesel kalkınmayı tetikleyecek düzeyde etkin hale gelmesinin, 1990'lardan sonra hızla gelişen bilgi ve iletişim teknolojileri, özellikle "ağ yapıları" sayesinde olduğu görülmektedir.

Yirminci yüzyılın sonlarına doğru küreselleşme, yerelleşme kavramlarının birlikte gelişmesi ve merkezi kalkınma politika ve destek programlarının başarısızlığı, yerel kalkınma bakış açısının ön plana çıkmasını sağlamış, bu kapsamda da "girişimcilik ve inovasyonun yerel kalkınmada çekirdek rolü üstlendiği" deneyimler ile ortaya konmuştur (Kuah, 2002).

\section{KÜMELENME VE BÖLGE EKONOMISII}

Bilindiği gibi "bölge", tanımı gereği doğal ekonomik bir alandır. Uygun idari araçlar ve küme geliştirme faaliyetleri ile bu alan, ekonomik bir çıkar alanı haline getirilir. Ekonomik çıkar alanının oyuncuları "bölge ekonomisi”ni oluşturur. Porter'ın bakış açısı ile "bölge", "küme alanı" ile paralel kullanılmaktadır. Bölge ekonomisinin aktörlerini oluşturan yapıların başında işletmeler yer almaktadır. Bunun yanı sıra, bölgesel kamu otoritesi, üniversiteler ve tüm eğitim kurumları, işbirliği kurumları ile sivil toplum kuruluşları, danışmanlık firmaları, teknoloji geliştirme merkezleri, 
teknoparklar, kuluçkalıklar ve tüm bu yapıların ulusal ve uluslararası bağlantıları da bölge ekonomisinin aktörleridir (Cook ve Memedovic, 2003).

Kümenin ve girişimcilerin rekabetçiliği için kümenin iç ve diş çevre koşulları ile bunlarla etkileşimi, ayrıca aktörlerin yapısı ve aralarındaki ilişkilerden kaynaklanan küme iç dinamiği önemlidir. Söz konusu bileşenlerin her bölgeye göre farklılık göstermesi ve iç dinamiklerinin farklı olması, her bölgenin gelişim hikayesinin farklı olmasına ve bu nedenle ekonomisinin farklı gelişmesine neden olur. Bu nedenle bölge ekonomisi ile ilgili ileriye yönelik bir senaryo tasarlayabilmek için, geçmişinin çok iyi anlaşılması, bu bileşenler bazında iç dinamiklerin iyi analiz edilmesi gerekmektedir (Feldman ve Francis, 2006).

Küme çevre koşullarını ve dinamizmini şekillendiren de kümelenme politikasıdır. Kümelenme politikası, makro kalkınma sektörleri olarak bilinen sanayi, tarım, inovasyon, girişimcilik, bölgesel kalkınma, istihdam, eğitim ve uluslararasılaşma politikalarının kesit alanında (cross cutting) yer alır ve hepsinin eşgüdümlü ve birbirlerini tamamlayacak şekilde çalışmasını gerektirir. Kümelenme politikası doğrultusunda tasarlanacak kümelenme desteklerinin küme çevre koşulları ve küme dinamizmini geliştirmesi, desteklemesi beklenmektedir.

Bölge ekonomisi ve iç dinamiklerinin gelişim süreci ile ilgili olarak Amerika Birleşik Devletlerinde Silikon Vadisi ve Capitol Bölgesinde mukayeseli bir analiz çalışması yürütülmüştür. Bu çalışma sonucunda, Silikon Vadisindeki gelişmenin elektronik sanayinde güçlü bir kaç girişimcinin bölgeyi geliştirmek üzere ortaya koyduğu vizyon, plan, program ve projelerin uygulanması ile, diğer taraftan Capitol bölgesindeki gelişmenin yerel hükümetin tasarruf tedbirlerine bağlı olarak bir çok kişiyi işten çıkartması ile işsiz kalanlara yönelik "iş edindirme" amaçlı ortaya koyduğu girişimcilik ve inovasyon destekleri sayesinde olduğu ortaya çıkmıştır (Feldman ve Francis, 2006).

\subsection{Kümelenme ve Girişimcilik}

Grişimciliğin başlangıcı, doğası gereği "yerel bir vaka"dır. Aslında "girişimcilik daha önceki deneyimlerin veya büyük şirketlerin girmeye değer bulmadığı piyasadaki boşlukları dolduran ilgilerin neticesi"dir. Çağımızda girişimci "iş çevresinin tamamlayıcı bir parçası"dır ve bu kapsamda "çevre koşullarını şekillendiren ve aynı zamanda çevre koşulları tarafından da şekillendirilen"dir. Girişimcilikte karar süreci, "girişimcinin tercihlerinin, fırsatların ve sermaye kaynaklarına ulaşabilmenin karmaşık bir bileşenidir" (Feldman ve Francis, 2006).

Girişimciler için yerel bağlantılar, irtibatlar ve iş çevresine ilişkin bilgi birikimi önemlidir. Girişimciliğin ortaya çıkmasında girişimcilik ile ilgili gömülü bilginin kendisini göstermesinde kamu politikalarının rolü önemlidir. Girişimcilikte bölge ekonomisi aktörlerinin, bir başka ifade ile küme aktörlerinin oluşturduğu çevre koşulları karar sürecinde etkendir.

Kümelenmenin başarı ile uygulandığı gerek bir çok Avrupa Birliği ülkesinde, gerek Amerika Birleşik Devletlerinde, küme geliştirme planını oluşturan stratejik yol 
haritasında yer alan eylemlerin büyük ölçüde "girişimcilik ve inovasyon" kaynaklı olduğu görülmektedir. Çünkü kümeyi oluşturan oyuncular arasında girişimciler değer zincirinin tamamlanmasını sağlayan ve belli bir coğrafyada ekonomi yaratılmasını sağlayan ana oyunculardır. Söz konusu ana oyuncuların yüksek katma değerli ürün üretmesi, bir başka ifade ile inovasyona yönelik faaliyet göstermesi de yerel refahın yükseltilmesi açısından tercih edilen bir hususdur.

\subsection{Kümelenme ve İnovasyon}

Bilindiği gibi geçen yüzyılın ortalarından itibaren "inovasyon, girişimciliği tamamlayan bir kavram olarak gündemde yer almaya başlamış olup, gün geçtikçe girişimciliğin içerisindeki önemi pekişmiştir. "Girişimci Tek Başına İnovasyon Yapamaz" ilkesi kapsaminda,

- İnovasyon için birçok kuruluşun karşılıklı etkileşim ve ağ yapı özellikleri ile bir "eko inovasyon sistemi" oluşturduğu ve

- $\quad \mathrm{Bu}$ ağ yapı ilişkileri içerisinde "bilgi ve becerilerin dolaşarak yeni teknolojileri yaygınlaştırdığı ve ayrıca öğrenme, yeni beceriler kazanma gibi ekonomik gelişmenin temeline katkı sağladığı da ortaya konmuştur (Charles, 2008).

İşletmelerin faaliyetlerinin belli bir alanda yoğunlaşması ve ihtisaslaşması "inovasyon için uygun ortamın bir başka ifade ile gerekli kaynakların ve ağ ilişkilerinin oluşmasını" sağlamaktadır. Yerel ekonomide üretimin ihtisaslaşarak bir eko inovasyon sistemi yaratması, bölgeselleşme ve küreselleşme kavramlarının ortaya çıkması ile beraber, ilk defa 1992'de "Bölgesel İnovasyon Sistemi" (BİS) olarak anılan bir kavramın ortaya çıkmasını sağlamıştır (Charles, 2008).

1998'de Michael Porter, yerel rekabetçilik ile ilgili "rekabet elmas modeli"ni ortaya koyduğunda, "ABD'de rekabetçiliğin küme tabanına dayal BİS'ler sayesinde geliştiğini" belirtmiştir. Bu doğrultuda, 1998'den sonra BİS ve küme politikaları paralel yürütülmüştür.

\subsection{Kümeler ve Bölgesel İnovasyon Sistemi}

Bölgesel İnovasyon Sistemi, "belli bir coğrafi alanda inovasyonun bilgi üreten kurumlar, firmalar, yerel otoritelerin, formal veya informal ilişkiler üzerinden, kurumsal çerçeve desteği ile gerçekleştirilmesi" olarak tanımlanmaktadır (Cook ve Memedovic, 2003).

Diğer taraftan kümelenme süreci ile ilgili birçok tanım incelendiğinde, "aynı veya benzer sektörlerde bilgi üreten kurumlar, firmalar ve yerel otoritelerin, formal veya informal ilişkiler üzerinden değer zincirini tamamlaması ve yerel hasılanın bir ekonomik alan yaratmak üzere gerçekleştirilmesi” gibi bir yaklaşım görülmektedir. 


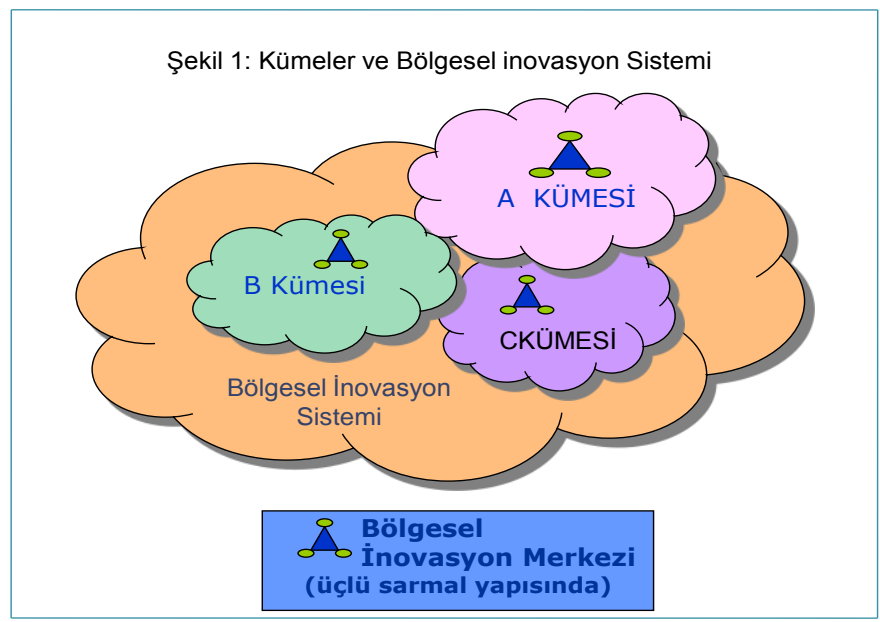

Bu bağlamda bölge ekonomisi yaratmak üzere bir bölgesel inovasyon sistemi içerisinde, Şekil 1'de görülebileceği gibi, sektörel olarak farklılaşmış birden fazla küme olabileceği görülmektedir. Deneyimler, her kümenin içerisinde de kümenin sektörü ile ilgili bir BİS olabileceğini ortaya koymuştur. Kümenin içerisindeki BİS, kümenin itici gücü olarak kümeye hizmet sağlamaktadır (Contardi, 2009). Bu konu ile ilgili olarak, birçok örneğe, Fransa'nın makro kümelenme projesi olan "Rekabet Kutupları Projesi"nde rastlamak mümkündür. Çünkü Fransa'da kümelenme yaklaşımından makro düzeyde bilim ve teknoloji politikalarının uygulama aracı olarak yararlanılmıştır. AB'nde BİS ile ilgili destek mekanizmaları 1995'den sonra devreye girmiştir. Almanya ve İngiltere'de BİS, 1990'dan sonra Ar-Ge politikası, bölgesel yapıları güçlendirme ve bilgi tabanlı sanayi politikasının uygulama aracı görevini görmüştür. Ekonomik Gelişme için İşbirliği Teşkilatı (OECD) uzman raporları, BİS yaklaşımından bölgesel inovasyonu güçlendirmek üzere yararlanılmasını ve bunun bölgesel kalkınma ajansları tarafından uygulamasının yapılmasını önermektedir (Charles, 2008).

\section{KÜME OLUŞUMU VE REKABETÇİLIK}

"Bölge" ve "küme alanı" kavramlarının eşdeğer anlamda kullanıldığı hususuna bir önceki bölümde değinilmişti. Bölgesel rekabetçiliği etkileyen unsurlar küme bazında irdelendiğinde temel bileşenlerin "küme dinamiği" ve "küme çevresi" olduğu görülmektedir. Bunlar birlikte makro düzeyde kümelenme politikası için temel oluşturmaktadır (Şekil 2). 


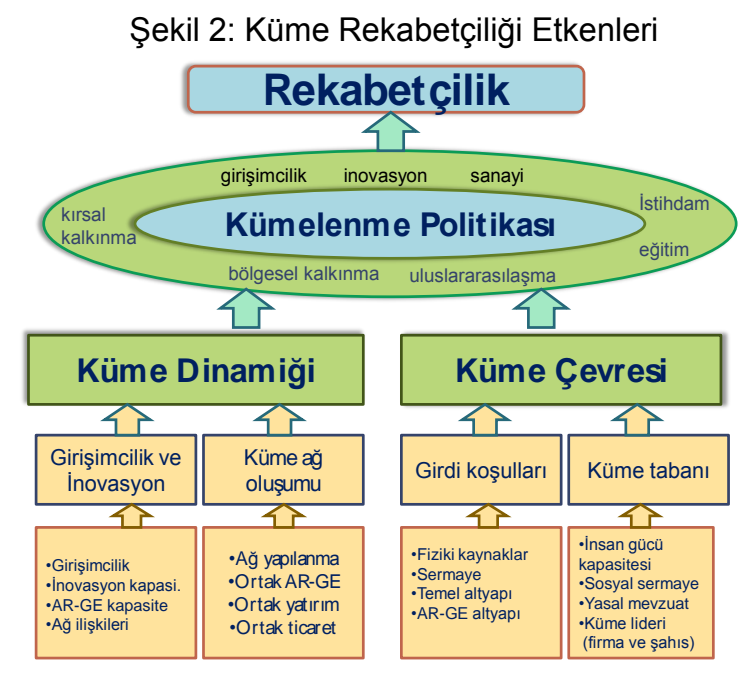

Şekil 2'de belirtildiği gibi, küme dinamiğini etkileyen unsurların başında girişimcilik ve inovasyon kapasitesi ile ağ yapılanmaya yatkınlık ve bunların iş ilişkilerine yansıma düzeyi ile ortak eylem gerçekleştirme seviyesi yer almaktadır.

Yine aynı Şekilde görülebileceği gibi, küme çevre koşullarını şekillendiren hususlar büyük ölçüde kümenin analizinde göz önünde bulundurulması gereken girdi koşulları olup bunlar, fiziki kaynaklar, bilgi kaynakları, mali kaynaklar ile altyapı imkanlarıdır. Diğer taraftan "küme tabanı" olarak anılan, kümeye temel teşkil eden koşullar da küme çevresinin oluşumunda etkin faktörlerdendir. Mevzuat, sosyal sermaye, Ar-Ge için altyapı imkanları v.b. bunların arasında yer almaktadır. Küme çevresi ve küme dinamiği ile ilgili belli bir temel mevcut ise, kümelenme politikası ve bunu şekillendiren girişimcilik, inovasyon, sanayi, tarım, eğitim, istihdam ve bölgesel kalkınma politikaları sözkonusu kümenin temelinin güçlenmesini ve rekabetçiliğin gelişmesine katkı sağlayabilir.

OECD LEED uzmanları, küme oluşumunda rekabetçiliği etkilemek üzere "küme dinamiği ve küme çevresini etkileyen unsurların", üç tematik alanı kapsadığını belirtmektedir (OECD LEED, 2005). Bu unsurlar aşağıda yer almaktadır:

a) Küme Stratejisi; aşağıdaki hususlardan birisine yönelik veya bir kaçını kapsayacak şekilde olabilir;

- Yerel ve bölgesel kalkınma,

- Sanayide rekabetçiliğin yükseltilmesi,

- Doğrudan yabancı yatırımcı çekilmesi,

- İnovasyonun geliştirilmesi,

- KOBİ desteği geliştirme

b) Küme Program Tasarımı; somut destek mekanizmalarını kapsamaktadır;

- Piyasa arızalarının azaltılması, 
- Sürdürülebilirliğin teşviki,

- Küme özelinde iş destek hizmetlerinin sunulması,

- Destek programlarının entegre edilerek sunulması,

- Finansal desteklerin firmaların özel ihtiyaçlarına göre tasarlanması

- Küme hibe fonlarından yararlananların "projenin izleme ve değerlendirmesi"ni zorunlu olarak yerine getirmesi

c) Küme Yönetimi; kümenin uluslararasılaşması ile ilgilidir;

- Küme kavramına ilişkin bilinç geliştirme, farkındalık yaratma,

- Lider yetiştirme (küme içi birlikteliği sürdürme maksadıyla),

- Küme içi aktörlerin ortak proje geliştirmelerini teşvik etme,

- Kümenin sürekli tanıtımı ve kümeye katılımını teşvik etme,

- Küme uzmanlığ1 ve yetkinliğinin (competencies) oluşturulması amacıyla, ağ oluşumunun teşvik edilmesi ve böylece kümenin bu alanda yetkinliğinin geliştirilmesi,

- Sosyal sermayenin geliştirilmesi (özellikle küme yöneticileri ya da kolaylaştırıcılarının önemli bir görevi olarak),

- Küme içinde veya dış dünya ile iletişim, bilgi ve deneyim paylaşımına açık bir sistem kurulması

\section{TÜRKIYYE'DE KÜME OLUŞUMUNU VE SÜRDÜRÜLEBİLİRLİĞİII DESTEKLEYEN PROGRAMLAR}

Ülkemizde küme oluşumu ve bunu tetikleyen girişimcilik ve inovasyon desteği de dahil olmak üzere, ayrıca sürdürülebilirliği de destekleyen programlar;

1. Kalkınma Bakanlığı Destekleri (Kalkınma Ajansları Hibeleri),

2. Bilim, Sanayi ve Teknoloji Bakanlığı Destekleri (KOSGEB, TÜBİTAK Destekleri, IPA III ile Tekno Girişim, Santez, v.b. destekler)

3. Ekonomi Bakanlığının Destekleri (Dış Ticaret Müsteşarlığının sağladığı destekler)

4. Gıda, Tarım ve Hayvancılık Bakanlığı Destekleri (Kırsal Kalkınma, TEDGEM, IPARD kapsamındaki destekler)

5. Çalışma ve Sosyal Güvenlik Bakanlığı Destekleri (IPA IV kapsamındaki destekler) şeklinde çok geniş bir yelpazade sunulmaktadır.

Bunlardan teklife çağrı usulu ile hibeden hak kazananları belirlemeye yönelik destek programları kapsamında, projenin iç tasarımı ile ilgili olarak, (i) küme dinamiğini geliştirmeye veya (ii) küme çevre koşullarını geliştirmeye yönelik faaliyetler tasarlamak, mümkün olabilir. Dolayısıyla projeyi hazırlayan uzman danışman kişilerin bu alandaki kişisel bilgi, beceri ve birikimleri önem kazanmaktadır. 
Bunun yanı sıra projeyi değerlendiren kesimin de aynı şekilde benzer bilgi beceri ve birikime sahip olarak projeyi değerlendirmesi beklenmektedir. Kalkınma Ajansları, KOSGEB'in İşbirliği ve Güç Birliği Destek Programı ile Gıda Tarım ve Hayvancılık Bakanlığının destekleri bu grup altında değerlendirilebilir.

Diğer taraftan söz konusu Bakanlıkların bir kısmında halen kümelenmeye yönelik destek programları olmasa da girişimcilik ve inovasyonu destekleyen programları nedeni ile kümelenme destekleri ile eş güdümlü çalışması sağlandığı takdirde küme gelişimi konusunda aşama kaydedilmesi mümkün olabilir. Bu eşgüdümün sağlanması da ana kalkınma sektörleri olarak anılan sanayi, tarım, bölgesel gelişme, girişimcilik, eğitim, istihdam gibi alanlardaki destek programlarının eşgüdümlü çalışması ya da "kümelenme politikası"nın hayata geçirilmesi ile mümkündür.

Kümelenme Politikası konusunda $\mathrm{AB}$, Merkezi ve Doğu Avrupa ülkeleri ile katılım öncesi ülkelerde yapılan bir araştırma, söz konusu ülkelerin \% 67'sinde kümelenme politika dokümanının olduğunu ortaya koymuştur. Ancak özellikle AB ülkelerinde bilim teknoloji ve yenilikçilik politikalarının kümelenmeye temel teşkil edecek yönde şekillendirildiği görülmüştür (Oxford Research AS, 2008). Bunların çoğunda kümelenme, girişimcilik ve inovasyona dayalı olarak desteklenmektedir. Ülkemizde halen yürürlükte resmi bir kümelenme politikası olmasa da birçok kurum ve kuruluşun kümelenmeyi destekleyen destek mekanizmalarını yürürlüğe koyduğu bilinmektedir.

\section{SONUÇ VE DEĞERLENDİRMELER}

Küme oluşumunun temel iki bileşeninin, (i) küme dinamiği ve (ii) küme çevre koşulları ile ilgili olduğu araştırma ve deneyimler ile ortaya konmuştur. Küme dinamiğinin harekete geçirilmesinde girişimcilik, inovasyon ve ağ yapılanma ile işbirliği ve güç birliğini tetikleyen unsurların önemli olduğu, diğer taraftan küme çevre koşulları olarak anılan yapının da insan kaynakları, fiziki kaynaklar ve sermaye ile ilgili "girdi koşulları ve küme tabanı" olarak anılan unsurlar tarafından şekillendirildiği belirlenmiştir. Bunların yanı sıra özellikle OECD kaynaklı çalışmalar, bu bileşenlerin geliştirilmesi için (i) kümelenme politikası, (ii) küme destek programları ve (iii) küme yönetimi alanlarındaki destek mekanizmaları olarak belirtilen üç tematik alanın zenginliğine dikkat çekmektedir.

Ülkemizde küme dinamiği ve küme çevre koşullarını geliştiren destek mekanizmaları mevcuttur. Bir başka deyiş ile girişimcilik, inovasyon, ağ yapılanma ya da insan kaynakları, semaye kaynakları ve altyapı imkanları ile ilgili destek programları yürürlüktedir. Ancak bunların bütünsel olarak bir küme veya daha genelde bir bölgeyi geliştirecek şekilde eşgüdümlü çalışmasını sağlayacak içeriğinin tekrar gözden geçirilmesi önerilmektedir.

Bunlara ilave olarak, bu destek programlarının "kümelenmeye yönelik destekler" olarak anılabilecek oldukça sınırlı sayıda destek mekanizmaları ile uyumlu 
ve eşgüdümlü çalışabilmesi yönünde de ayrıca bir çalışma yapılmasında yarar görülmektedir.

Söz konusu önerilerin gerçekleştirilmesi durumunda da uygulamada başarılı olunabilmesi açısından bu programların sahipliliğini yapan kurumlar arasında yönetişim ilkelerinin çok net çizilmesi gerekmektedir. Kümelenme politikası olarak anılan yapıdan da beklentilerimiz bu kapsamdadır. Bunlar yapıldığı takdirde kümelenme politikası, adı konmasa da, fiilen uygulamaya girmiş olacaktır.

Uygulamacılar tarafında karşılaşılan önemli bir sorun da, ülkemizde usulune uygun proje hazırlama ile ilgili olarak, gerek hazırlayanlar tarafında gerek değerlendiriciler tarafında kapasitenin daha fazla geliştirilmesine ihtiyaç duyulmaktadır. Bu kapsamda üniversitelerde proje hazırlama konusundaki eğitimlerin bütün fakülte ve bölümlerin öğrencilerin faydalanmasına imkan sağlayacak şekilde yaygınlaştırılarak organize edilmesinde yarar görülmektedir. Bu konu ile ilgili olarak karşılaşılan bir başka sorun da, ülkemizde devlet yardımlarına ilişkin "etki analizi" yapılmaması ile ilgilidir. Ülkemizde girişimcilik, inovasyon ve kümelenmeyi destekleyen devlet yardımlarının etki analizinin yapılmaması, uygulamadaki hataların devam etmesine neden olmaktadır. Devlet yardımlarının her birisi için, yardımı sağlayan kuruluşun "etki analizi modeli"ni en kısa sürede oluşturması önerilmektedir. Aksi takdirde hatalı, eksik ya da etkisiz devlet yardımları sunulmaya devam edilecektir.

\section{KAYNAKÇA}

Charles, D., Network and Cluster Policy in Europe: Lessons from RITTS and New Cluster Based Regional Innovation Strategies, Centre for Urban and Regional Development Studies, Institute for Policy and Practice, 2008.

Contardi, M., Territorial Partnership for SMEs Development and Competitiveness, (unpublished paper by Istituto Regionale di Recerca della Lombardia), 2009.

Cook, P., Memedovic, O., Strategies for Regional Innovation Systems: UNIDO, Vienna, 2003.

Feldman M. P., ve Francis, J., Entrepreneurs and the Formation of Industrial Clusters", Johns Hopkins University, yıl yazılacak

Kuah, A. T. H., Cluster Theory and Practice, Journal of Research in Marketing and Entrepreneurship, 4, 2002.OECD, The Subnational Review of Economic Development and Regeneration, July 2007, OECD.

OECD LEED, Business clusters; Promoting Enterprise in CEEC, OECD, 2005.

Oxford Research AS, Cluster Policy in Europe, Europe Innova Cluster Mapping Project, Brussels, 2008.

Porter, Michael, Competitive Advantage of Nations, States and Regions, Istanbul (paper presented in Istanbul organized by Turkcell), April 2009. 